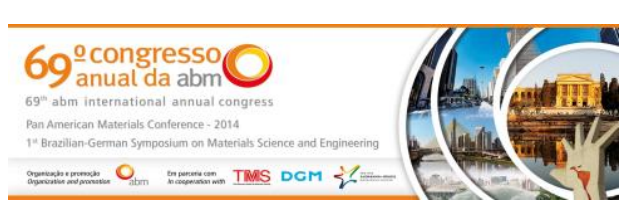

Tema: Metalurgia física e comportamento de materiais em temperaturas elevadas

\title{
INFLUÊNCIA DA MICROESTRUTURA NA RESISTÊNCIA A CORROSÃO SOB TENSÃO DE AÇOS HSS EM AMBIENTE AQUOSO CONTENDO H2S*
}

\author{
Rafael Utsch Braga ${ }^{1}$ \\ Dayanna Moreira Duarte 2 \\ Cesar Afonso Weis Olea ${ }^{3}$ \\ Vicente Tadeu Lopes Buono
}

Resumo

Neste trabalho foi analisada a influência da microestrutura de diferentes composições químicas de aço de alta resistência (HSS, do inglês High Strength Steel) na resistência à corrosão sob tensão assistida por sulfetos (SSC, do inglês Sulfide Stress Corrosion). Quatro aços ao boro com quantidades variáveis de $\mathrm{V}$ e Ti foram tratados termicamente para atingir propriedades mecânicas de aços de alta resistência. A resistência à corrosão do material foi avaliada de acordo com a norma NACE-TM0177 Método D, utilizando corpos de prova do tipo DCB. A microestrutura dos aços foi caracterizada utilizando microscopia eletrônica de varredura (MEV) através da análise de réplicas de carbono, por meio das quais foram determinados o tamanho e a distribuição dos precipitados, cuja composição química foi avaliada através de espectroscopia por dispersão de energia (EDS). Foi observada uma influência do teor de $\mathrm{V}$, sendo 0 acréscimo de $\mathrm{V}$ favorável ao aumento da resistência à corrosão. $\mathrm{O}$ aumento do tamanho médio de precipitados de CrMo através do coalescimento dos mesmos também mostrou-se eficaz para melhorar a resistência a corrosão sob tensão em meio contendo $\mathrm{H}_{2} \mathrm{~S}$. As propriedades mecânicas e o tamanho de grão foram também avaliados, no entanto sem encontrar correlação com a resistência a corrosão sob tensão.

Palavras-chave: Corrosão sob tensão; Vanádio; Titânio; Aço HSS

\section{INFLUENCE OF MICROSTRUCTURE ON SULFIDE STRESS CORROSION (SSC) RESISTANCE OF HIGH STRENGTH STEEL (HSS)}

\section{Abstract}

In this work, the influence of the microstructure of different chemical compositions of a high strength steel on sulfide stress corrosion(SSC) performance was analyzed in terms of type, size and distribution of precipitates. Four boron steels with different $\mathrm{V}$ and Ti contents were heat treated to achieve the mechanical properties of HSS. The corrosion resistance of the material was evaluated according to NACE TM0177 - Method D, using DCB test specimens. The microstructure of the steels was characterized by scanning electron microscopy (SEM) using carbon replicas to determine the size and distribution of precipitates, while their chemical composition was evaluated using energy dispersive spectroscopy (EDS). It was observed that the $\mathrm{V}$ content influenced SSC resistance The $\mathrm{V}$ additions were observed to improve SSC resistance. Furthermore, coarsening of CrMo precipitates is expected also to improve the SSC resistance of the material. The mechanical properties and grain size ranges evaluated in this investigation did not show any significant impact on SSC performance.

Keywords: High strength steel; Sulfide stress corrosion; Titanium; Vanadium.

1 Engenheiro Metalurgista, Aluno de Mestrado em Engenharia Metalúrgica, Programa de Pós-Graduação em Engenharia Metalúrgica, Materiais e de Minas da Escola de Engenharia da UFMG, Belo Horizonte, MG, Brasil.

2 Engenheira Metalurgista, Engenheira da Vallourec Tubos do Brasil S.A., Belo Horizonte, MG, Brasil.

3 Engenheiro Mecânico, Doutor em Engenharia Metalúrgica e de Materiais, Pesquisador da Vallourec Tubos do Brasil S.A., Belo Horizonte, MG, Brasil

4 Físico, Doutor em Engenharia Metalúrgica e de Minas, Professor do Departamento de Engenharia Metalúrgica e de Materiais da UFMG, Belo Horizonte, MG, Brasil.

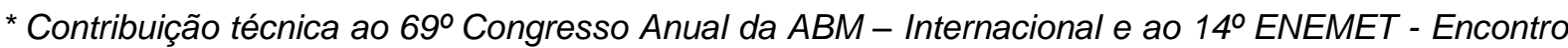
Nacional de Estudantes de Engenharia Metalúrgica, de Materiais e de Minas, 21 a 25 de julho de 2014, São Paulo, SP, Brasil.
} 


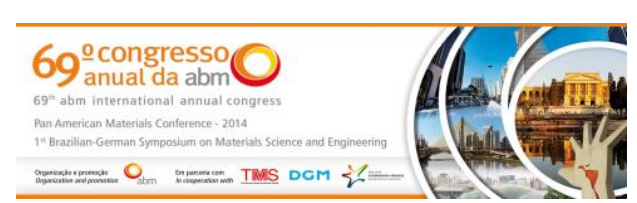

\section{INTRODUÇÃO}

Materiais para aplicações em poços petrolíferos são expostos a ambiente aquoso contendo ácido sulfídrico $\left(\mathrm{H}_{2} \mathrm{~S}\right)$, um componente que aparece naturalmente no petróleo cru e gás natural [1].

A fragilização dos aços devido ao $\mathrm{H}_{2} \mathrm{~S}$ é um problema para a indústria de petróleo desde 1950. Com o aumento da demanda, cada vez mais poços contendo $\mathrm{H}_{2} \mathrm{~S}$ são explorados. Assim, várias pesquisas vêm sendo realizadas no intuito de desenvolver materiais de maior resistência a este tipo de ambiente [1].

Tubos sem costura são usados para a completação de poços offshore (revestimento de poços petrolíferos com tubos de aço seguidos de cimentação com concreto), assim, são a última barreira entre o poço perfurado e o ambiente, portanto é essencial que a sua integridade permaneça intacta enquanto o poço estiver em operação, evitando vazamentos em situações extremas [2].

No entanto, os mecanismos de fragilização em aços carbono microligados devido à presença de hidrogênio atômico em ambientes contendo $\mathrm{H}_{2} \mathrm{~S}$ ainda não é um fenômeno completamente compreendido. Analisando amostras rompidas em teste de corrosão sob tensão (CST), observa-se que a falha nestes materiais ocorre de forma intergranular, através da nucleação de trincas devido ao aprisionamento de átomos de hidrogênio e propagação de forma frágil ao longo da microestrutura [3].

Sabe-se, também, que dentre as diversas características microestruturais, o tamanho, distribuição e tipo de carbonetos presentes interferem na quantidade de sítios de aprisionamento de átomos de hidrogênio e, consequentemente, na resistência à nucleação e propagação de trincas frágeis quando o aço é tensionado em ambiente aquoso contendo $\mathrm{H}_{2} \mathrm{~S}$ [2-4]. De uma forma geral, cada aço possui uma quantidade crítica de hidrogênio absorvido $(\mathrm{Hc})$ a partir da qual absorções além dessa quantidade podem gerar a uma falha por hidrogênio [3-5].

Assim, é importante avaliar quais características microestruturais destes precipitados (tamanho, quantidade, morfologia, tipo, distribuição) são as mais críticas para a resistência do material à corrosão sob tensão.

Este trabalho visa estudar a influência dessas características microestruturais, com foco na precipitação de carbonetos, sobre os mecanismos de aprisionamento de hidrogênio que levam a nucleação e propagação de trincas de forma frágil em aço submetido à tensão em ambiente aquoso contendo $\mathrm{H}_{2} \mathrm{~S}$.

Para tanto, foram utilizadas análises microestruturais e ensaios mecânicos em aços com diferentes composições químicas e rotas de tratamento térmico. Comparando estes resultados com os de resistência a corrosão sob tensão, é possível indicar quais são as características do material que afetam a sua resistência a corrosão sob tensão.

\section{MATERIAIS E MÉTODOS}

Neste trabalho foram utilizados aços cujas faixas de composição química estão descritas na Tabela 1. Conforme observado, tratam-se de aços ao boro com variações nos teores de $\mathrm{Ti}$ e $\mathrm{V}$.

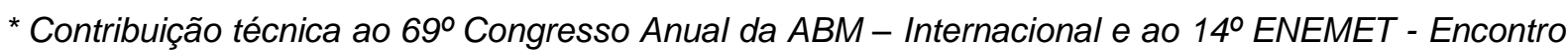
Nacional de Estudantes de Engenharia Metalúrgica, de Materiais e de Minas, 21 a 25 de julho de 2014, São Paulo, SP, Brasil.
} 


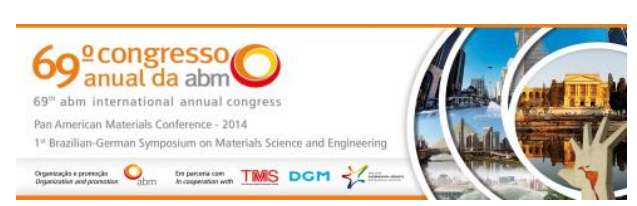

Tabela 1. Faixa de composição dos aços utilizados (\%peso)

\begin{tabular}{c|c|c|c|c|c|c|c}
\hline Material & $\% \mathrm{C}$ & $\% \mathrm{Mn}$ & $\% \mathrm{Cr}$ & $\% \mathrm{Mo}$ & $\% \mathrm{~V}$ & $\% \mathrm{~B}$ & $\% \mathrm{Ti}$ \\
\hline Aço 1 & $<0,35$ & $<1,2$ & 0,4 a 1,5 & 0,25 a 1,00 & $>0,02$ & 0,0010 & $>0,03$ \\
Aço 2 & $<0,35$ & $<1,2$ & 0,4 a 1,5 & 0,25 a 1,00 & $<0,01$ & 0,0010 & $<0,02$ \\
Aço 3 & $<0,35$ & $<1,2$ & 0,4 a 1,5 & 0,25 a 1,00 & $<0,01$ & 0,0010 & $>0,03$ \\
Aço 4 & $<0,35$ & $<1,2$ & 0,4 a 1,5 & 0,25 a 1,00 & $>0,02$ & 0,0010 & $<0,02$ \\
\hline
\end{tabular}

Os lingotes foram laminados e em seguida tratados termicamente (diferentes condições de têmpera e revenimento) para obtenção de propriedades de grau C110, conforme Tabela 2. Sendo:

- Rota 1: Austenitização (aproximadamente $900^{\circ} \mathrm{C}$ ); têmpera em água e revenimento;

- Rota 2: Austenitização (aproximadamente $900^{\circ} \mathrm{C}$ ); têmpera em água e revenimento com cerca do dobro do tempo de encharque da Rota 1;

- Rota 3: Austenitização (aproximadamente $900^{\circ} \mathrm{C}$ ); têmpera em água e revenimento com tempo equivalente a soma dos tempos de revenimento das rotas 1 e 2 .

Após o tratamento térmico, foram retiradas amostras para ensaios de tração e corrosão sob tensão (ensaio NACE método D usando corpo de prova do tipo DCB Double Cantilever Beam) de cada material. Este ensaio fornece uma medida quantitativa da resistência à propagação da trinca ( $\left.\mathrm{K}_{1 \mathrm{ssc}}\right)$, possibilitando avaliar o efeito microestrutural correspondente a cada aço em relação a sua resistência à corrosão.

A partir do tratamento térmico, cada condição de tratamento e composição química recebeu uma denominação de A a I (presente na Tabela 2), considerada doravante neste artigo. Todo o material foi temperado em água após cada processo de austenitização e resfriado ao ar após cada revenimento. Ensaios de dureza em escala Vickers (HV10) e medições de tamanho de grão austenítico foram realizados no corpo de prova DCB após corte transversal depois de findado o ensaio de corrosão.

Tabela 2. Tratamento térmico realizado nos materiais em estudo

\begin{tabular}{c|c|c}
\hline Amostra & Aço & Tratamento térmico \\
\hline A & Aço 1 & Rota 1 \\
B & Aço 4 & Rota 2 \\
C & Aço 1 & Rota 3 \\
D & Aço 4 & Rota 1 \\
E & Aço 2 & Rota 1 \\
F & Aço 2 & Rota 1 \\
G & Aço 3 & Rota 1 \\
H & Aço 4 & Rota 3 \\
I & Aço 1 & Rota 2 \\
\hline
\end{tabular}

* Contribuição técnica ao $69^{\circ}$ Congresso Anual da ABM - Internacional e ao 14ํㅡㄹ ENEMET - Encontro Nacional de Estudantes de Engenharia Metalúrgica, de Materiais e de Minas, 21 a 25 de julho de 2014, São Paulo, SP, Brasil. 


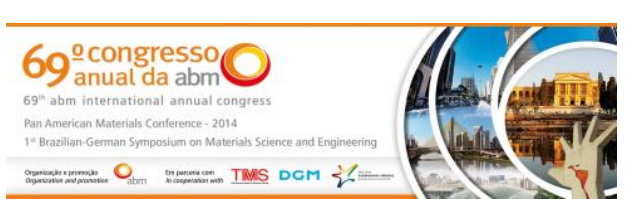

Para avaliação do comportamento dos materiais listados, estudos estatísticos de experimentos (DOE - Design of Experiments e ANOVA) foram propostos, sendo eles:

1. Um estudo de análise do efeito da composição química realizado em 2 fatores (teores de Ti e $\mathrm{V}$ ) em 2 níveis (<0,02\% e $>0,04 \%$ de $\mathrm{Ti}$ e $<0,01 \%$ e $>0,04 \%$ de V);

2. Um estudo da análise do efeito das rotas de tratamento térmico;

Após os ensaios de corrosão, foram cortadas secções transversais de cada material (A a l) para retiradas de réplicas da microestrutura e posterior avaliação dos precipitados através de microscopia eletrônica de varredura (MEV).

As réplicas foram obtidas através de um recobrimento com grafite da superfície das amostras atacadas com Nital 5\%. Após o recobrimento, as amostras foram imersas em solução de Nital $10 \%$ e as réplicas coletadas com o auxílio de pinça e grades finas de cobre. Um diagrama esquemático da metodologia está descrito na Figura 1.

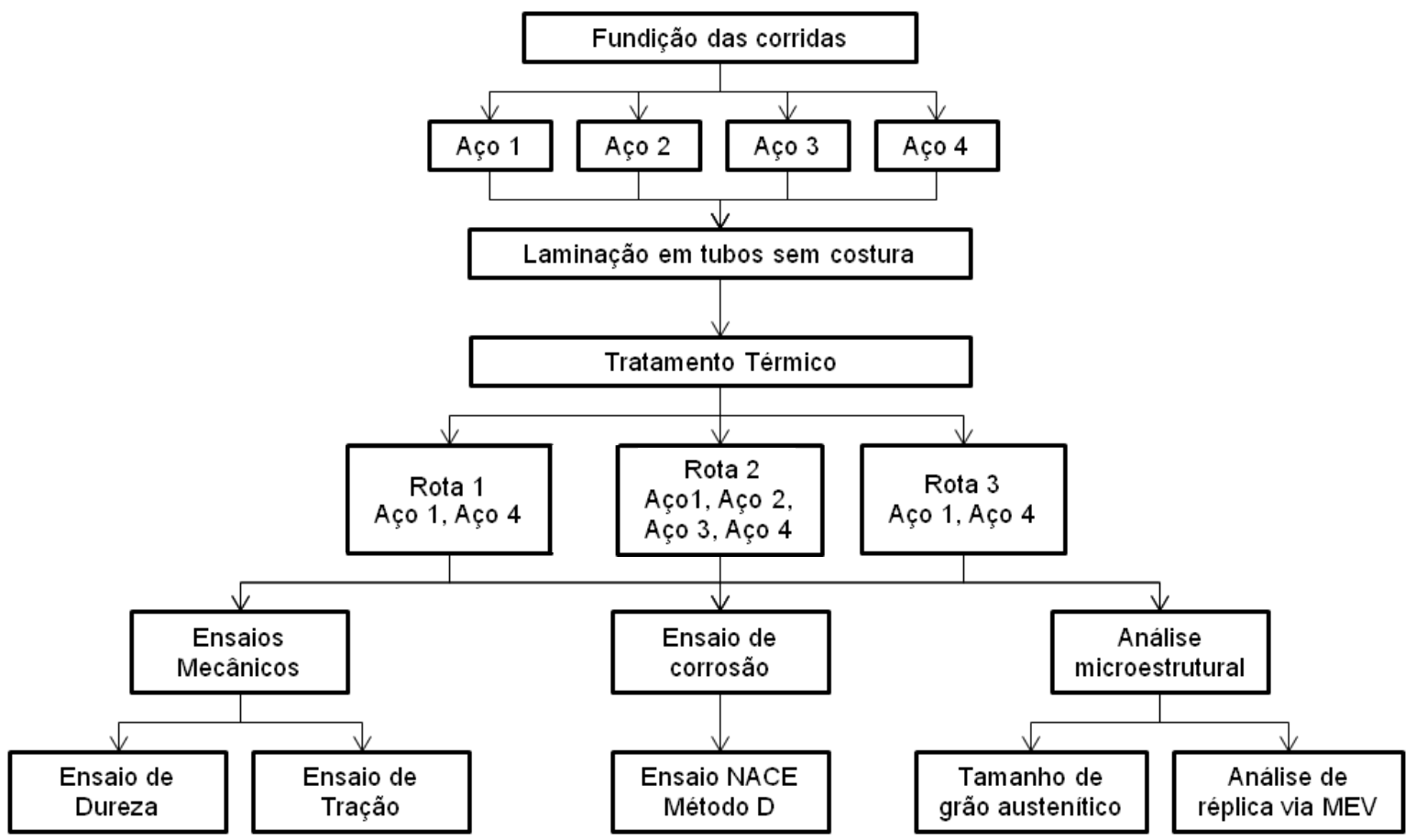

Figura 1. Diagrama esquemático da metodologia utilizada.

\section{RESULTADOS E DISCUSSÃO}

Os resultados dos ensaios de tração e dureza realizados após tratamento térmico estão descritos na Tabela 3 e Tabela 4.

Tabela 3. Resultados de ensaio de tração e dureza por aço após tratamento térmico

\begin{tabular}{c|c|c|c}
\hline Aço & LE médio* (MPa) & LRT médio* (MPa) & Dureza média (HV10) \\
\hline Aço 1 & 820 & 880 & 276 \\
Aço 2 & 797 & 942 & 268 \\
Aço 3 & 819 & 855 & 267 \\
Aço 4 & 817 & 860 & 269 \\
\hline
\end{tabular}

*LE = Limite de Escoamento; LRT = Limite de Resistência à tração.

\footnotetext{
* Contribuição técnica ao 69ำ Congresso Anual da ABM - Internacional e ao 14ํㅡㄹ ENEMET - Encontro Nacional de Estudantes de Engenharia Metalúrgica, de Materiais e de Minas, 21 a 25 de julho de 2014, São Paulo, SP, Brasil.
} 


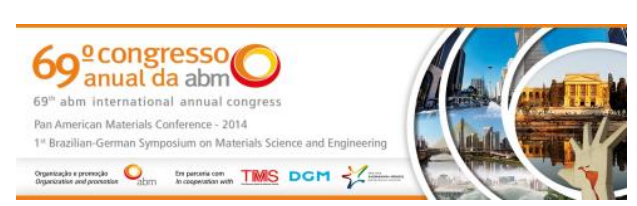

Tabela 4. Resultados de ensaio de tração e dureza após rotas de tratamento térmico

\begin{tabular}{c|c|c|c}
\hline Rota & LE médio* (MPa) & RT médio* $(\mathrm{MPa})$ & Dureza média (HV10) \\
\hline 1 & 860 & 942 & 284 \\
2 & 795 & 867 & 264 \\
3 & 805 & 855 & 275 \\
\hline
\end{tabular}

*LE = Limite de Escoamento; LRT = Limite de Resistência à tração.

As mesmas amostras dos ensaios submetidas a ensaio de tração e dureza foram também submetidas a ensaio de corrosão sob tensão NACE método D. Os resultados do teste de corrosão estão descritos na Tabela 5.

Tabela 5. Resultados de ensaios de corrosão sobtensão NACE método D

\begin{tabular}{c|c|c|c}
\hline Aço & KISSC - MPa.m1/2 & Rota & KISSC - MPa.m1/2 \\
\hline Aço 1 & 32,78 & 1 & 31,49 \\
Aço 2 & 30,25 & 2 & 32,25 \\
Aço 3 & 31,3 & 3 & 36,16 \\
Aço 4 & 35,2 & & \\
\hline
\end{tabular}

Após o teste de corrosão, foram realizadas medidas de tamanho de grão austenítico e análise microestrutural da seção transversal do corpo de prova testado. Os valores de tamanho de grão estão descritos na Tabela 6.

Tabela 5. Resultados de medidas de tamanho de grão austenítico

\begin{tabular}{c|c|c|c|c|c}
\hline Aço & $\begin{array}{c}\text { Tamanho de } \\
\text { Grão } \mu \mathrm{m}\end{array}$ & $\begin{array}{c}\text { Tamanho de } \\
\text { Grão ASTM }\end{array}$ & Rota & $\begin{array}{c}\text { Tamanho de } \\
\text { Grão } \mu \mathrm{m}\end{array}$ & $\begin{array}{c}\text { Tamanho de } \\
\text { Grão ASTM }\end{array}$ \\
\hline Aço 1 & 6,9 & 11,1 & 1 & 7,5 & 10,9 \\
Aço 2 & 6,7 & 11,2 & 2 & 6,7 & 11,2 \\
Aço 3 & 6,4 & 11,3 & 3 & 6,6 & 11,2 \\
Aço 4 & 6,9 & 11,1 & & & \\
\hline
\end{tabular}

Para uma melhor análise dos resultados, um estudo estatístico DOE foi realizado. Primeiramente, foi estudado o efeito da composição química na resistência a corrosão sob tensão. Todos os dados considerados nessa análise foram retirados de amostras com mesmo processamento (Rota 1).

$A$ análise estatística mostra que o teor de $V$ influi positivamente no valor de $K_{\text {Issc, ou }}$ seja, o acréscimo de $\mathrm{V}$ aumenta a resistência à corrosão sob tensão do aço (conforme Figura 2). No entanto, o teor de Ti não influi nos valores de Kıssc, ou seja, não afeta a resistência a corrosão sob tensão do material, para a faixa de composição de ambos os elementos ( $\mathrm{V}$ e Ti) estudada neste trabalho. A Figura 3 apresenta esse resultado de forma gráfica através dos efeitos padronizados das variáveis na resposta (KIssc). As análises foram realizadas com $95 \%$ de confiança (alpha $=0,05)$. Nesse gráfico, os pontos pretos indicam variáveis cujo efeito no KIssc é irrelevante, assim como os pontos vermelhos indicam variáveis que influem efetivamente na resposta (KIssc).

\footnotetext{
* Contribuição técnica ao 69ำ Congresso Anual da ABM - Internacional e ao 14ํㅡㄹ ENEMET - Encontro Nacional de Estudantes de Engenharia Metalúrgica, de Materiais e de Minas, 21 a 25 de julho de 2014, São Paulo, SP, Brasil.
} 


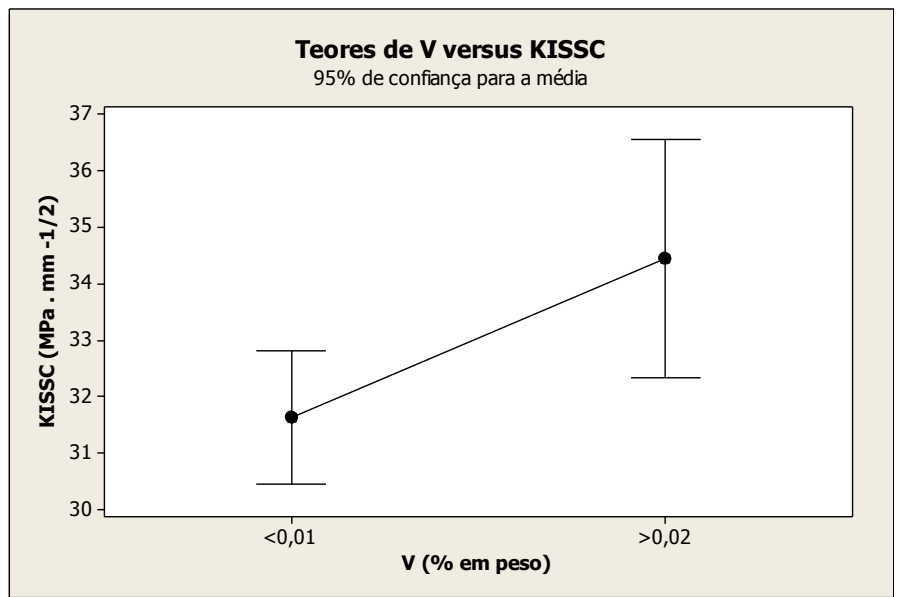

Figura 2. Influência do teor de $V$ no Kıssc.

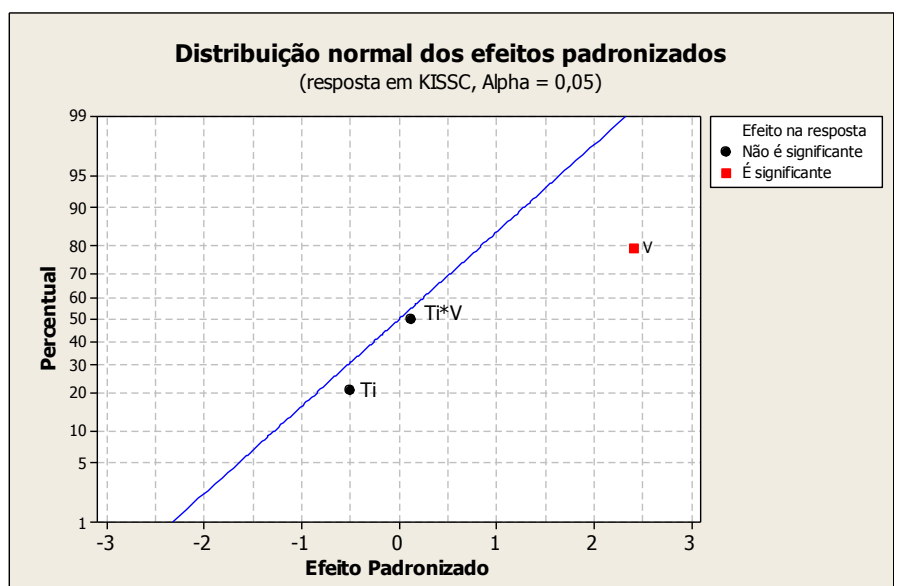

Figura 3. Efeitos das variáveis (teores de Ti e V) na resposta (Kıssc).

A partir dessa análise, foi feito outro estudo estatístico (ANOVA) para avaliação do efeito dos ciclos térmicos, considerando-se apenas as amostras de aço contendo V. O resultado indica um efeito positivo em relação aos ciclos térmicos, conforme Figura 4.

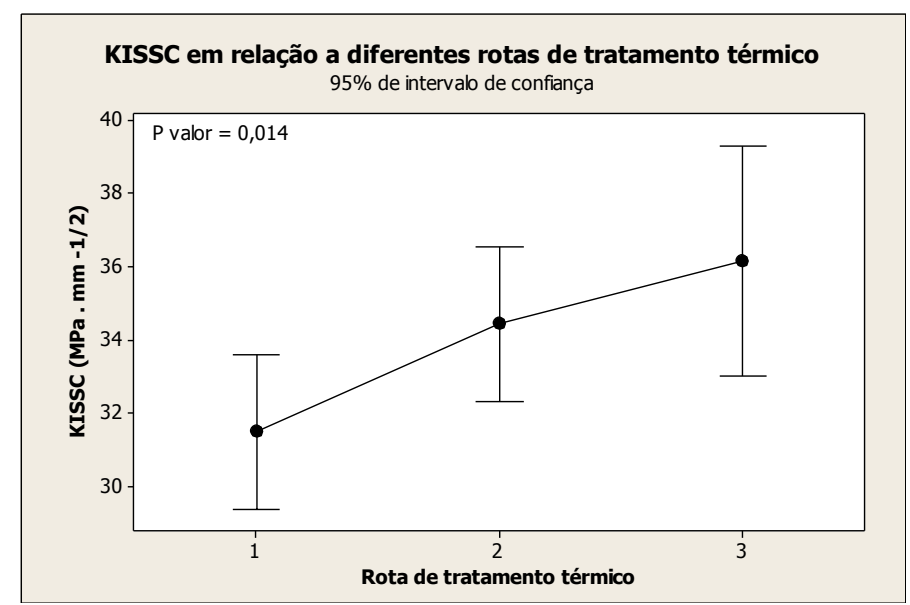

Figura 4. Efeito dos ciclos térmicos no valor de KISsc.

\footnotetext{
* Contribuição técnica ao 69 Congresso Anual da ABM - Internacional e ao 14ํㅡㄹ ENEMET - Encontro Nacional de Estudantes de Engenharia Metalúrgica, de Materiais e de Minas, 21 a 25 de julho de 2014, São Paulo, SP, Brasil.
} 


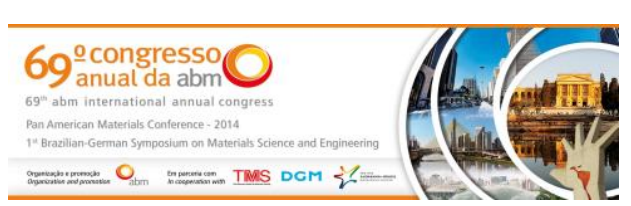

Da mesma forma, foram analisadas as influências das propriedades mecânicas na resistência a corrosão sob tensão. Essa análise também foi feita somente nas amostras contendo V. Os resultados estão ilustrados na Figura 5.
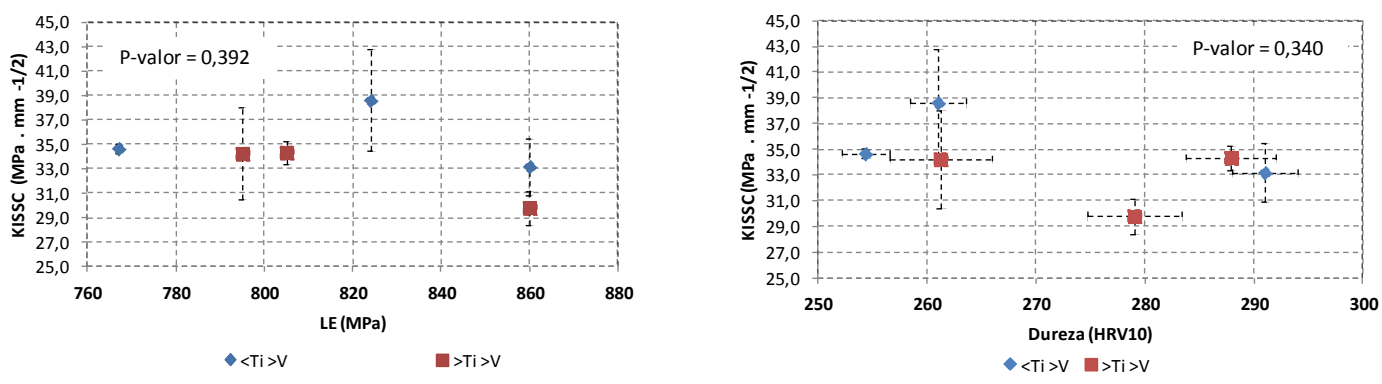

Figura 5. Efeito do limite de escoamento (LE, à esquerda) e dureza (à direita) no valor de Kıssc.

Conforme apresentado na Figura 5, podemos concluir que não há efeitos aparentes das propriedades mecânicas ( $\mathrm{P}$-valor $>0,05$ indica que não há correlação entre a variável e a resposta).

As variações no tamanho de grão apresentadas entre as amostras são muito pequenas (vide Tabela 5). Assim, quando comparamos os tamanhos de grão das amostras do mesmo aço submetidas a diferentes tratamentos térmicos não se consegue distinguir diferença entre os tamanhos de grão observados, ou seja, os tamanhos de grão das amostras deste estudo estão dentro de uma variação normal do material, não sendo essa uma característica significativamente afetada pelo processamento.

$\mathrm{Na}$ segunda etapa deste estudo, visou-se compreender as causas do aumento da resistência a corrosão sob tensão com o acréscimo de $\mathrm{V}$ e devido ao efeito do tratamento térmico.

Conforme observado na Figura 6 , os precipitados presentes nos aços tendem a coalescer conforme a rota de tratamento utilizada. De acordo com a Figura 6, os precipitados presentes na Rota 3 aparentam estar mais coalescidos do que os presentes na Rota 1, que por sua vez estão mais coalescidos que os da Rota 2. Nas Figuras 7 e 8 estão indicados os precipitados que foram encontrados nos diversos tipos de aço. Os precipitados presentes na Figura 7 foram encontrados mais facilmente nas amostras com maior teor de Ti (amostras A, C, G e I), enquanto que os precipitados descritos na Figura 8 foram encontrados em todas as amostras. Os picos de $\mathrm{Cu}$ e Al são derivados do suporte das amostras e o pico de $\mathrm{C}$ é devido ao recobrimento com filme de $\mathrm{C}$ utilizado para extração das réplicas.

\footnotetext{
* Contribuição técnica ao 69ํ Congresso Anual da ABM - Internacional e ao 14ํㅡㄹ ENEMET - Encontro Nacional de Estudantes de Engenharia Metalúrgica, de Materiais e de Minas, 21 a 25 de julho de 2014, São Paulo, SP, Brasil.
} 

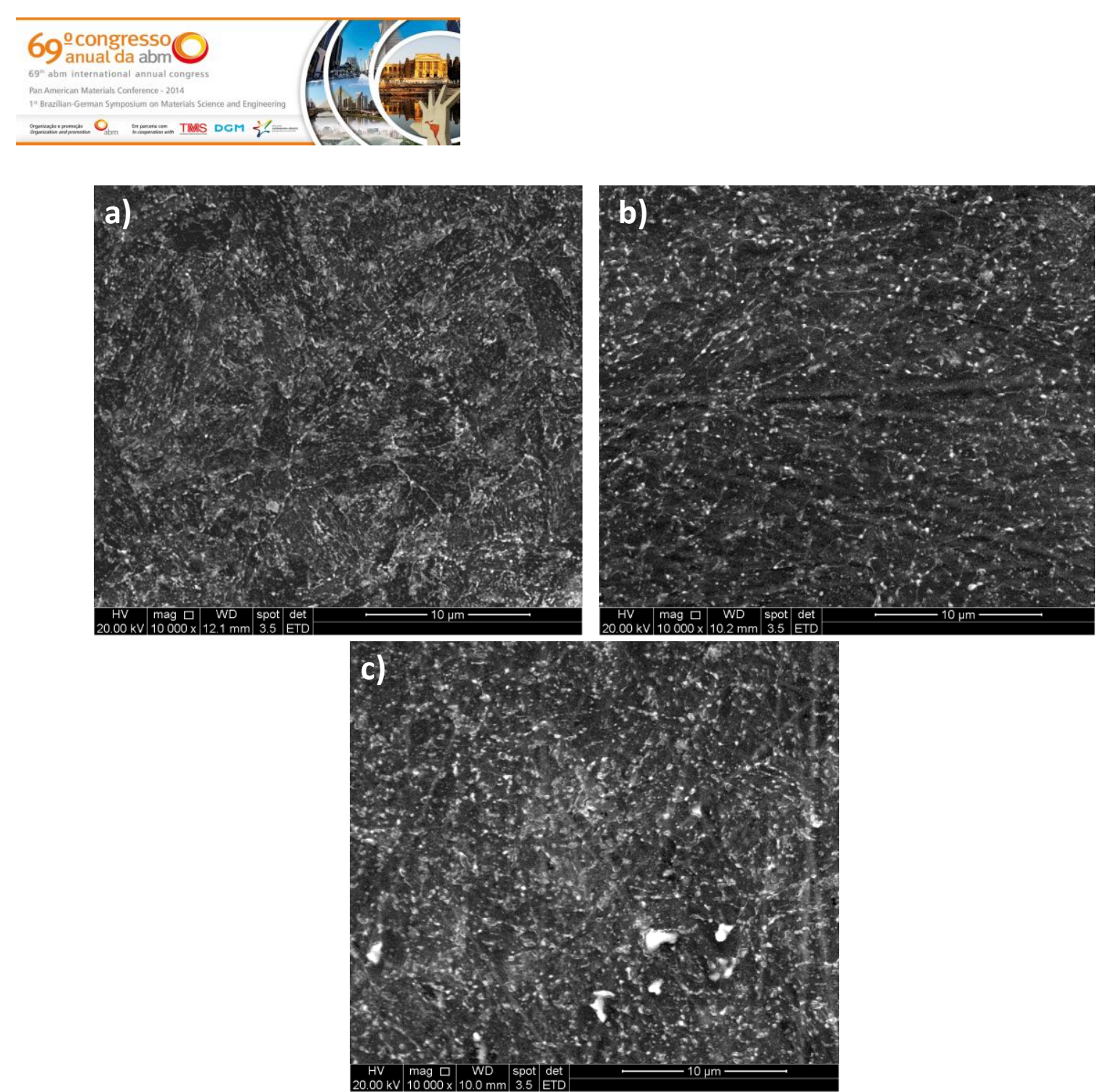

Figura 6. Aspecto geral dos precipitados após a) Rota 2 (amostra B), b) Rota 1 (amostra D) e c) Rota 3 (amostra H).
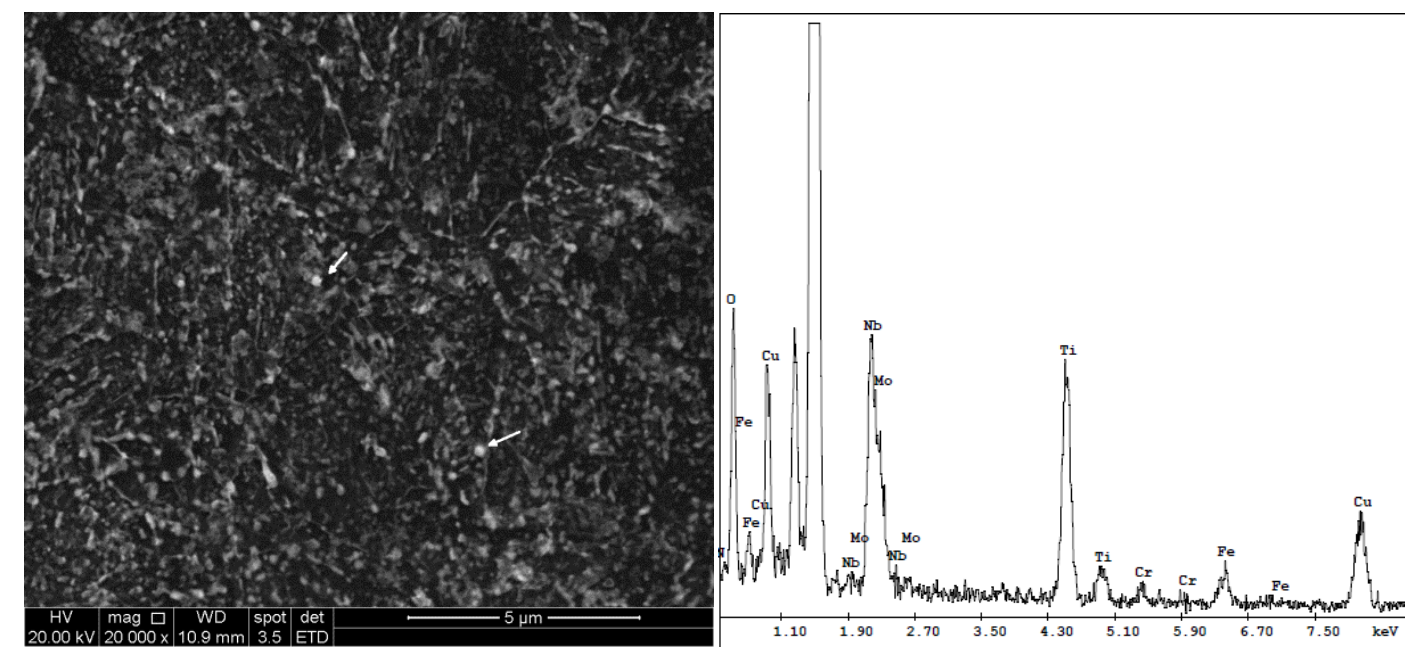

Figura 7. Precipitado de Nb e Ti (indicados com setas, EDS ao lado), amostra G.

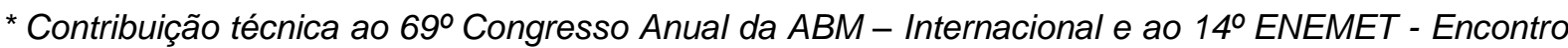
Nacional de Estudantes de Engenharia Metalúrgica, de Materiais e de Minas, 21 a 25 de julho de 2014, São Paulo, SP, Brasil.
} 


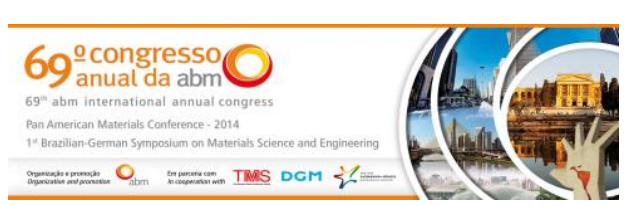

devido ao aumento do Hc do material, ou mesmo devido a redução da quantidade de deslocações presentes após o revenimento.

Outro fator de relevância para a resistência a corrosão sob tensão foi o tratamento térmico. Foi constatado que, dependendo da rota, maior é a resistência a corrosão sob tensão do material. Esse comportamento pode ser atribuído ao coalescimento dos precipitados de CrMo, observado por MEV, que induz o aprisionamento de hidrogênio pela interface incoerente desses precipitados, evitando que este se concentre em locais que levem a fragilização do material, como contornos de grão austenítico, aumentando enfim a resistência a corrosão sob tensão em presença de $\mathrm{H}_{2} \mathrm{~S}$.

\section{Agradecimentos}

Os autores gostariam de agradecer à Vallourec Tubos do Brasil S.A., à Coordenação de Aperfeiçoamento de Pessoal de Nível Superior (CAPES/PROEX), Brasília, DF e ao Laboratório de Microscopia Eletrônica do Departamento de Engenharia Metalúrgica e de Materiais da Universidade Federal de Minas Gerais (DEMET/UFMG).

\section{REFERÊNCIAS}

1 Loucachenko N, Bourges P, Orie KE, Chauvy C, Coudreseuse L, Toussaint P. Recent experience on sour service resistant steels behaviour, NACE Corrosion Conference \& Expo. 2009.

2 Kushida T. Low alloy steel for oil country tubular goods and method of making. Sumitomo Metals Industries, Osaka-Japão. 2001; US 6267828

3 Perez TE. Corrosion in the Oil and Gas Industry: An Increasing Challenge for Materials. JOM. 2013; Volume 65, No 8

4 Tarui T, Kubota M. Approaches for Fundamental Principles 1:Evaluation Method of Hydrogen Embrittlement and Improvement Techniques of Delayed Fracture, Nippon Steel Tech. Rep. 2012

5 Yamasaki S, Kubota M, Tarui T. Evaluation Method for Delayed Fracture Susceptibility of Steels and Development of High Tensile Strength Steels with High Delayed Fracture Resistance, Nippon Steel Tech. Rep.. 1999.

6 Li Y, Milbourn D. Use of Vanadium in Long Steel Products, Vanitec Ltd. Winterton House, Westerham, Inglaterra

7 Yamasaki S, Bhadeshia HKDH. M4C3 precipitation in Fe-C-Mo-V steels and relationship to hydrogen trapping, Proceedins of The Royal Society A. 2006; 462: 2315-2330

8 Yokota T, Shiraga T. Evaluation of Hydrogen Content Trapped by Vanadium Precipitates in a Steel. ISIJ International. 2003; 43(4): 534-538

9 Beachem CD. A new model for hydrogen-assisted cracking (hydrogen embrittlement). Metall. Trans. 1972; 3: 437-451

10 Ganglokk RP. Hydrogen Assisted Cracking of High Strength Alloys. In: Milne I, Ritchie $\mathrm{RO}$, Karihaloo B. Comprehensive Structural Integrity.New York: Elsevier Science; 2003, p. 31-101

\footnotetext{
* Contribuição técnica ao $69^{\circ}$ Congresso Anual da ABM - Internacional e ao 14ํㅡㄹ ENEMET - Encontro Nacional de Estudantes de Engenharia Metalúrgica, de Materiais e de Minas, 21 a 25 de julho de 2014, São Paulo, SP, Brasil.
} 